\title{
Risk Analysis System in Geriatric Care
}

\author{
M.A. Nikolaeva \\ Department of Computer Science and Robotics \\ Ufa State Aviation Technical University \\ Ufa, Russia \\ e-mail:marina_danicheva@mail.ru
}

\author{
A.I. Agadullina \\ Department of Computer Science and Robotics \\ Ufa State Aviation Technical University \\ Ufa, Russia \\ e-mail: aygul.agadullina@gmail.com
}

\section{M.I. Dolganov \\ Republican Clinical Hospital of War Veterans \\ Ufa, Russia}

\begin{abstract}
$^{1}$
This paper describes the geriatric analysis system which accounts for group as well as individual risks of patients. A review of studies related to various aspects in geriatrics is provided. The purpose of the study, along with tasks to be solved, main modules and users of the geriatric risk analysis system are discussed.
\end{abstract}

\section{Introduction}

In modern society, an increase in the average life expectancy and the general aging of the world population present a considerable problem. According to forecasts, by 2050 , the proportion of the world's population over 60 years will increase to $22 \%$ [1].

The prevalence of mortality among people aged 60 years and older compared to other age groups is due to the predisposition of the aging organism to diseases and injuries [2, 3].

Elderly people over the age of 65 have accumulated various health problems evident by exhibited clinical as well as age-related manifestations, i.e., senile asthenia, weight loss, trips and falls, cognitive impairment, decreased functional activity and mobility, polypharmacy, etc. Risk factors for survival are closely related to the effects of impairments due to said problems.

Thus, much consideration has been given recently to a comprehensive geriatric assessment of the condition of elderly people, with the aim of identifying relevant clinical and geriatric manifestations to provide timely and adequate geriatric care.

\section{The current state of the problem}

A number of studies reflect various aspects of the stated topic [4-12]: from general questions about geriatric assessment of health status in old age to solving specific problems (i.e., building geriatric maps, choosing treatment methods, evaluating treatment effectiveness, assessment of the risk level of the elderly).

This article discusses researches related to:

1. Study of geriatric problems.

2. Improving the methodology of a comprehensive geriatric assessment of the elderly;

3. Impact analysis of a comprehensive geriatric assessment in regard to prevention, treatment and life expectancy of the elderly;

4. Risk analysis for treatment of specific diseases.

In [8], issues of a comprehensive geriatric assessment for analysis of geriatric problems and functional status of elderly patients in order to provide timely appropriate medical care are considered.

[4] is describing construction of an integrated geriatric assessment algorithm, which, in contrast to the standard (symptomatic) examination, includes such stages as studying the patient's condition, and health, a comprehensive and interdisciplinary assessment of the state of physical and mental health, social relations, and overall satisfaction with the quality of life.

In [5], the concept and methods of a comprehensive health status assessment for an elderly person are proposed. Examples of health assessment for elderly patients, including their physical health (trophological status, functional status, and psychological state) are presented.

In [10], studies were conducted to analyze the effect of a comprehensive geriatric assessment on the probability of hospitalization during the first 3 months or the probability of survival after transcatheter aortic valve implantation. The results of the study prove the effectiveness of using some aspects of a comprehensive geriatric assessment. 
It was shown in [7] that a comprehensive geriatric assessment is an auxiliary tool for developing an appropriate therapeutic strategy in geriatric oncology. A comprehensive geriatric assessment, represented by a set of tools and indicators, to determine the therapeutic solution allows health care providers to develop an individual treatment plan for patients.

[9] is discussing issues related to the analysis of the impact of a comprehensive preoperative geriatric assessment on the risks of postoperative complications and functional disorders in the elderly.

In [6], studies related to assessing the impact of a comprehensive geriatric assessment on life expectancy after emergency hospitalization were carried out.

Studies related to risk assessment in the treatment of specific diseases, as a rule, use different scales, calculators, and models to divide research objects into groups for further treatment and prevention of the disease, taking into account various risk components [11$12]$.

[11] is researching use of modern predictors for the risk of complications and mortality necessary for choosing a sound method for the treatment of elderly and senile colon cancer patients, taking into account the prevalence of the disease and associated pathology. Examples of the use of modern scales, calculators and questionnaires to assess functional, physical and psycho-emotional status of this category of patients in order to determine the risk group of possible complications for the patient and his or her further treatment are given.

In [12], an approach to preventive health care for older people with high risk is proposed. Various models are considered, such as Adjusted Clinical Groups, Hierarchical Condition Categories, Elderly Risk Assessment, Charlson Comorbidity Measure, and Minnesota Tiering, which allow classification of elderly people according to risk level taking into account various indicators in order to provide timely preventive medical care.

Also, several articles are devoted to the identification of geriatric problems [13-16].

The "Crystal" Study [13] carried out a comprehensive study of geriatric manifestations, which helped to identify priority problems of elderly people and determine the strategy and tactics of their observation.

The SAGE study [14] analysed the indicators of health and quality of the elderly's life. The results demonstrate high prevalence of geriatric manifestations in Russia.

The PROMETEY study [15] concentrated on the prevalence of cognitive impairment in elderly patients who first came to an outpatient neurological appointment. According to the results obtained, every fourth patient has low ratings of neuropsychological scales.

However, despite the significant amount of research in this scientific field, in these works the issues related to the assessment, management of individual and group risks and the formation of individual patient profiles are not sufficiently considered. Also, the specificity of the subject area requires an integrated approach to assessing the health of older people.

Risk analysis and risk management will probably reduce the mortality of the elderly. It is proposed to draw a conclusion about the need to create a geriatric risk analysis system based on the relevance of the work.

\section{System description}

\subsection{System purpose}

The geriatric risk analysis system is designed to

- process the results of a comprehensive study for geriatric patients;

- identify and assess individual and group risks in geriatrics;

- manage risks associated with selection of an effective treatment and prevention methodology;

- $\quad$ predict the life quality of older people.

\subsection{Tasks solved by the system}

The developed geriatric risk analysis system is designed to solve two main problems:

1. Analysis of individual and group risks in geriatrics.

2. Formation of an individual patient profile for selection of medical and preventive measures that are necessary to improve the quality of life as well as life expectancy of older people.

The first task is related to:

1. Formation and use of a profiles database for groups of elderly people to identify features of age-related diseases;

2. Medical statistical analysis of patient data in geriatrics to assess the impact of clinical manifestations of geriatric problems and assessment of the most significant factors affecting the duration and quality of life;

3. Formalization of concepts and processes associated with risks in geriatrics, and selection of appropriate risk measures;

4. Identification, assessment and management of individual risks of patients, which can arise a priori (before treatment), in process and a posteriori (after medical intervention);

5. Assessment and management of group risks in geriatrics,

6. Formation of risk maps.

The second task is related to:

- Formation of an individual patient profile in geriatrics; 
- Prediction of patient condition with age-related pathology;

- Formalization of processes and treatment methods in geriatrics, analysis and selection of the optimal treatment plan for a particular patient.

\subsection{Subsystems of geriatric risk analysis system}

The developed software product consists of modules / libraries. Each subsystem is a separate functional module that implements a set of functions for solving problems of certain categories. This will allow using the developed algorithms also outside this project. The information about patients is recorded in the system as geriatric patient card with results of comprehensive assessment. Data can be entered repeatedly over time, which will create the basis for the dynamics of research. It is planned to implement the delimitation of user rights to ensure information security of the system.

The geriatric risk analysis system, according to the developers, will consist of the following subsystems:
- $\quad$ Subsystem of work with data;

- Subsystem of geriatric risk analysis;

- Subsystem "Service".

\section{4. Modules of system}

The geriatric risk analysis system consists of the following modules (Fig. 1):

- Maintaining geriatric cards;

- Geriatric calculators;

- Statistical data analysis;

- $\quad$ Risk analysis;

- $\quad$ Formation of risk maps;

- Formation of treatment methods;

- Formation of an individual treatment technique;

- Assessment of the effectiveness of treatment methods.

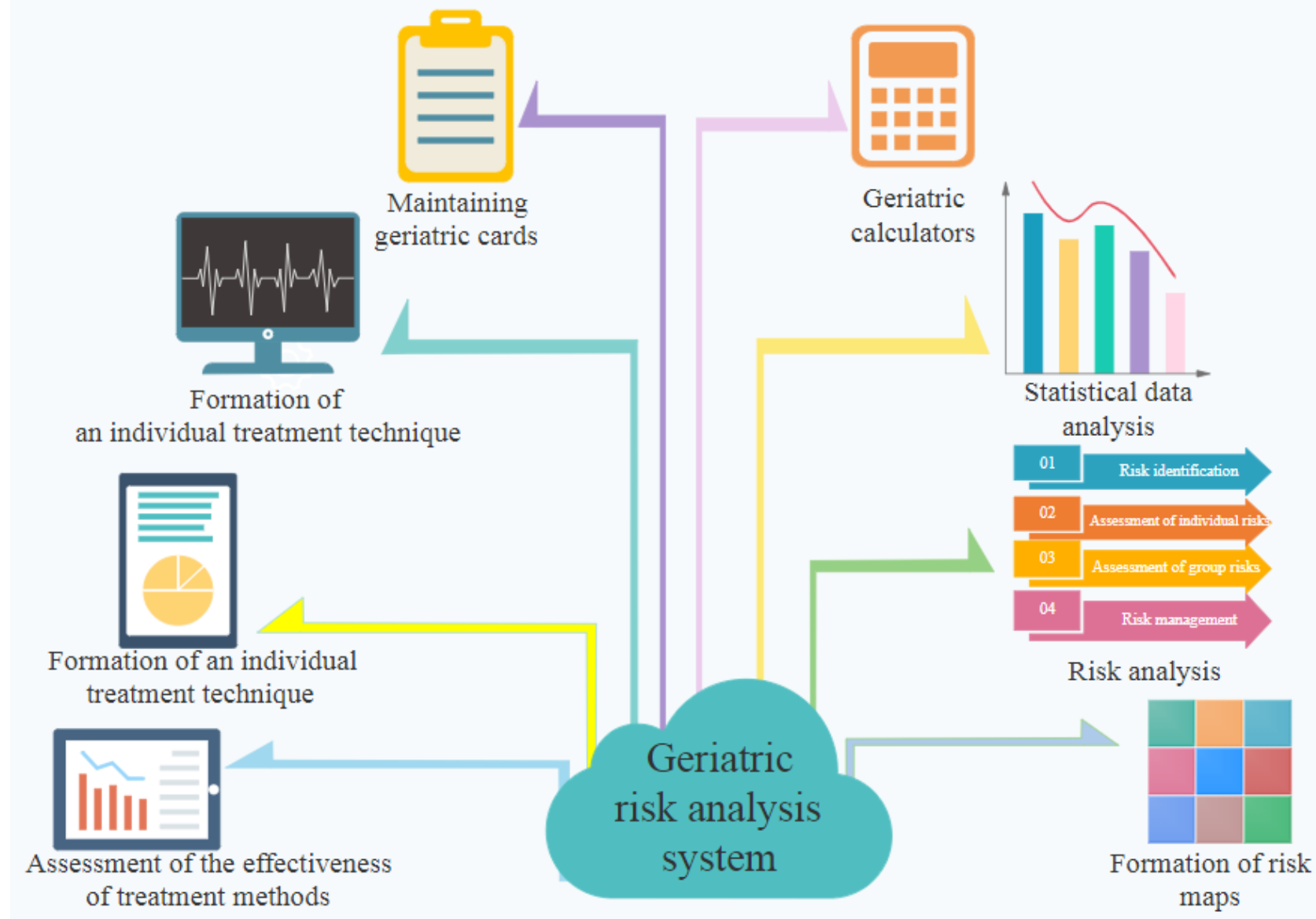

Fig 1. Modules of system

\section{Module "Maintaining geriatric maps"}

Purpose: formation, editing, storage and processing of data included on the patient's geriatric card in digital version.

A comprehensive assessment of the geriatric patient is quite voluminous. In addition to general information, it contains data about chronic diseases, drug therapy, risk factors for chronic noncommunicable diseases, presence of chronic pain, presence or absence of geriatric problems as well as issues associated with movement, mental and physical condition, self-assessment of health, and laboratory research results as well as health statements issued by health care providers along with their recommendations to patients, etc. Since the structure of 
the card is already established, we suggest expanding its fields for research, in particular, with a map of risks existing for geriatric patients.

Input: data obtained during the survey, results of geriatric calculators.

Output: data for statistical analysis, risk analysis, some individual risk assessments.

\section{Module "Geriatric Calculators"}

Purpose: assessment of geriatric patients to identify indicators of physical and mental health, sociodemographic status, etc.

A module has been developed for a comprehensive assessment of an elderly patient, consisting of a set of calculators, such as:

- CKD-EPI - a method to assess the glomerular filtration rate;

- CHA2DS2-VASc - a scale to assess the risk of thromboembolic complications in patients with atrial fibrillation / flutter;

- SCORE (Systematic Coronary Risk Evaluation) - a scale to assess the risk of a person dying from cardiovascular disease over the next 10 years;

- CAT - a test to assess the severity of chronic obstructive pulmonary disease;

- $\quad$ and others (a total of 13 calculators).

The following aspects were taken into account when formalizing the data of calculators:

- $\quad$ purpose of the calculator;

- input data;

- $\quad$ scale and grading, interpretation of grading;

- $\quad$ output data;

- connection with the results of other calculators and the further use of the obtained indicator.

Input: personal data of the patient, clinical indicators, results of a survey (questionnaire).

Output: estimates of the studied indicators (index values) with interpretation of the results.

\section{Module "Statistical Data Analysis"}

Purpose: accumulation and processing of information for medically relevant statistical data analysis in geriatrics.

The purpose of the procedures implemented in this module is to

1. Organize profiles of geriatric patients in three age groups:

- from 64 to 74 years of age,

- from 75 to 84 years of age,

- 85 years and more.
The profiles for each group contain identified age-related diseases, probability estimate for presence of clinical and geriatric issues, risks of age groups associated with treatment, quality of life, and the problem of survival;

2. Assess the most significant factors affecting the duration and quality of life of geriatric patients;

3. Create individual patient profiles in geriatrics, along with risk maps;

4. Predict indicators related to treatment and preventive activities.

Input: geriatric maps, official statistics, regulatory indicators.

Output: statistics of clinical, geriatric studies.

\section{Module "Risk Analysis"}

Purpose: research and solution of individual and group risk management problems in geriatrics.

Studies about geriatric risks are related to the formalization of risks, the choice of risk measures, the establishment of a relationship between existing, developed scales and risks, and the classification of risks. The Table 1 shows one of the types of geriatric risk classification associated with the treatment process.

Table 1 Geriatric Risk Classification

\begin{tabular}{|c|c|c|}
\hline A priori risks & Process risks & $\begin{array}{c}\text { A posteriori } \\
\text { risks }\end{array}$ \\
\hline $\begin{array}{c}\text { Risks of primary } \\
\text { diagnosis errors }\end{array}$ & $\begin{array}{c}\text { Risk of disease } \\
\text { exacerbation }\end{array}$ & $\begin{array}{c}\text { Risk of reduced } \\
\text { quality of life }\end{array}$ \\
\hline $\begin{array}{c}\text { Risk of delayed } \\
\text { treatment } \\
\text { (delayed } \\
\text { initiation of } \\
\text { treatment) }\end{array}$ & $\begin{array}{c}\text { Risk of getting the } \\
\text { disease out of } \\
\text { control } \\
\text { (instability) }\end{array}$ & $\begin{array}{c}\text { Risk of } \\
\text { choosing an } \\
\text { ineffective } \\
\text { treatment }\end{array}$ \\
\hline $\begin{array}{c}\text { Risk of urgent } \\
\text { hospitalization }\end{array}$ & $\begin{array}{c}\text { Risk of drug } \\
\text { incompatibility } \\
\text { (adverse drug } \\
\text { interactions) }\end{array}$ & $\begin{array}{c}\text { Risk of patient } \\
\text { dissatisfaction } \\
\text { with treatment }\end{array}$ \\
\hline $\begin{array}{c}\text { Risks associated } \\
\text { with geriatric } \\
\text { problems }\end{array}$ & $\begin{array}{c}\text { Risk of allergic } \\
\text { reactions to the } \\
\text { drug }\end{array}$ & Risk of survival \\
\hline $\begin{array}{c}\text { Risks associated } \\
\text { with clinical } \\
\text { manifestations }\end{array}$ & $\begin{array}{c}\text { Risk of side } \\
\text { effects of } \\
\text { treatment }\end{array}$ & \\
\hline
\end{tabular}

All of these risks are individual. However, group risks are considered in the system for research, generalizations, warnings of negative events. As an example, we can consider the risk of senile asthenia, the classification of the patient's "fragility", which is specified in the study by the geriatric scales of the studied patients.

As a measure of risk, both quantitative and qualitative indicators were considered, i.e., probabilities of a dangerous condition, assessments on scales, integrated risk assessments. 
The risk analysis module includes the following procedures:

- Risk identification;

- Assessment of individual and group risks;

- $\quad$ Risk management.

It is proposed to use the following mathematical models when identifying and assessing individual and group risks:

1. Logic-probabilistic method (initiating events are events whose probabilistic characteristics are obtained from the medical-statistical analysis of geriatric data);

2. Logistic regression (a synthesis of formal and informal knowledge);

3. ROC analysis and the fuzzy cognitive maps used in the identification and assessment of group risk;

4. Clustering methods for the formation of risk groups;

5. Kaplan - Mayer models and the Cox model for assessing the risks of survival.

Risk management is presented in the system by:

- formation of risk maps;

- risk reduction in the formation of an individual treatment technique using the multicriteria assessment method and neural network modeling.

Input information: statistical analysis data, geriatric card data.

Output: individual risk maps; group risk assessment, risk management recommendations.

\section{Module "Formation of risk maps"}

Purpose: systematize and visualize risks of geriatric patients.

Individual risk maps are a visualization of significant qualitative and quantitative risk characteristics of the geriatric patient, for example, the severity of the manifestation of geriatric problems, the likelihood of the manifestation of the investigated negative event.

Group risk maps are associated with analysis and visualization of the risks significance in older people participating in the study, also with external statistics and modeling results.

Input: risk analysis results, geriatric cards data.

Output information: patient risk assessment data tables; a table for each investigated geriatric problem that includes the risk significance on the scale of the probability of an adverse event occurrence and the scale for reduced quality of life (damage to health).

\section{Module "Formation of treatment methods"}

Purpose: construction and formalization of many treatment regimens for a particular nosology (disease).

The problem of formalizing and choosing a treatment methodology for groups or an individual geriatric patient is based on the guidelines titled "Pharmacotherapy in elderly and senile patients", including, in particular:

- polypharmacy issues (simultaneous, often excessive assignment of multiple drugs), methods for its prevention and correction;

- $\quad$ algorithms of patient management;

- $\quad$ issues of the effectiveness in use of certain drugs for elderly patients;

- potentially dangerous effects of taking medications for the elderly;

- description of the "7 steps" algorithm to reduce the risk of polypharmacy during pharmacotherapy of elderly patients [];

- monitored indicators and frequency of their determination for medication intake by the elderly.

Formalization of treatment approaches is associated with both drug treatment and physiotherapeutic treatment, consultations, care, etc.

Input: clinical guidelines, standards, risk assessments for geriatric patients.

Output: possible treatment and prevention regimens.

\section{Module "Assessment of the effectiveness of treatment methods"}

Purpose: multicriteria assessment of the effectiveness of medical intervention.

The dynamics of the performance indicators of the main body systems, the degree of patient satisfaction with treatment and the achieved level of quality of life were taken into account in the analysis of therapeutic and preventive measures effectiveness.

Input: change in clinical and geriatric indicators during treatment, duration and cost of treatment, survey results.

Output: rating of treatment methods.

\section{Module "Developing individual treatment approaches"}

Purpose: selection of the best set of treatment and prophylactic procedures for the patient.

An approach that uses graph algorithms and / or a neuronetwork approach are considered to select a technique for a particular class of geriatric patients. The best of the presented methods is selected, individually for each patient, taking into account the risk analysis,

Input: rating of methods for a specific patient, risk map.

Output: an individual profile of a geriatric patient, the appointment of individual treatment and prophylactic measures.

\section{System users}

Users of the software product can be students, graduates of medical universities, medical professionals with various levels of clinical experience, geriatricians of outpatient and inpatient care of various specifics. 
Installation of a system at their workplaces will allow achievement of a high level of automation for the processes of accumulation, processing and storage of information about elderly patients.

The base of the developed system can be updated on the basis of constantly updated information received in accordance with electronic administrative regulations from other information systems. In the future, it could be possible to implement interaction with other external systems when developing an information system.

\section{Conclusion}

Within the framework of studies on risk analysis in geriatrics, it is proposed to develop a pilot project of a medical information-analytical system for modeling the profile of the elderly population, with an assessment of group and individual risks of patients. Taking into account current body parameters of any patient, this system will allow to choose the necessary treatment and prevention program tailored to the needs of this specific individual in order to improve the quality of his life as well as his life expectancy.

The basis of the proposed approach is the synthesis of formal and informal knowledge in geriatrics.

In addition, for the first time, concepts and processes related to risk analysis in geriatrics are formalized, risk measures are specified into group and individual ones, along with methods for their identification and assessment.

As a result of the adaptation of well-known approaches to risk analysis and heuristics proposed by the authors, risk maps are developed as part of a comprehensive assessment of geriatric patients.

\section{Acknowledgments}

The results of the research presented in this article were supported by Grants RFBR № 19-07-00780.

\section{References}

1. World Health Organization, URL: https://www.who.int/news-room/factsheets/detail/ageing-and-health

2. Bakhmetova G.Sh. "Mortality in the elderly. Mortality: trends, study methods, forecasts. Collection of articles" / Ed. M.B. Denisenko, G.Sh. Bakhmetova - M .: MAKS Press, 2007, pp. 256-271. (in Russian).

3. Akhunova E.R., Abrosimova M. Yu. "Medical and statistical features of mortality of elderly people living in the urban area of the Republic of Tatarstan". In: Kazan Medical Journal, 2013, 94 (3), pp. 389-392. (in Russian).

4. Melekhin A.I. "Algorithm for a comprehensive geriatric assessment of health status in the elderly and senile age". In: Clinical and medical psychology: research, training, practice: electron. scientific journal, 2016, no. 3 (13) [Electronic resource]. URL: http://medpsy.ru/climp. (in Russian).

5. Frolova E.V, Korystina E.M "A comprehensive assessment of the health status of an elderly person and the possibility of its implementation in general medical practice". In: Russian Family Doctor, 2010, Vol. 14, no 1, pp. 12-23. (in Russian).

6. Ellis, Graham \& Gardner, Mike \& Tsiachristas, Apostolos \& Langhorne, Peter \& Burke, Orlaith \& H Harwood, Rowan \& Conroy, Simon \& Kircher, Tilo \& Somme, Dominique \& Saltvedt, Ingvild \& Wald, Heidi \& O'Neill, Desmond \& Robinson, David \& Shepperd, Sasha. (2017). Comprehensive geriatric assessment for older adults admitted to hospital. Cochrane Database of Systematic Reviews. 9. 10.1002/14651858.CD006211.pub3.

7. Pamoukdjian F., Liuu E., Caillet P., Gisselbrecht M., Herbaud S., Boudou-Rouquette P., Zelek L., Paillaud E. "Geriatric assessment and prognostic scores in older cancer patient: Additional support to the therapeutic decision?". In: Bull Cancer. 2017, Nov; 104(11):946-955. doi: 10.1016/j.bulcan.2017.10.004.

8. Carlson C., Merel S., Yukawa M. (2015). "Geriatric Syndromes and Geriatric Assessment for the Generalist". In: Medical Clinics of North America. 99. 10.1016/j.mona.2014.11.003.

9. Kumar C., Salzman B., Colburn J. (2018). "Preoperative Assessment in Older Adults: A Comprehensive Approach". In: American family physician. 98. 214-220.

10. Schoenenberger A.W., Werner N., Bramlage P., Martinez-Selles M., Maggi S., Bauernschmitt R., Thoenes M., Kurucova J., Michel J.-P., Ungar A. (2013). "Comprehensive geriatric assessment in patients undergoing transcatheter aortic valve implantation-rationale and design of the European CGA-TAVI registry". In: European Geriatric Medicine. 5. 10.1016/j.eurger.2013.10.001.

11. Gordeev S.S., Kovaleva Yu.Yu., Rasulov O.A. "Methods of comprehensive geriatric assessment of older patients with rectal cancer". In: Colorectal Oncology, Vol. 7, 2017, pp. 43-52. 10.17650/22203478-2017-7-2-43-52 (in Russian).

12. Shankar Vuppalapati, Jaya, Kedari, Santosh, Ilapakurti, Anitha, Vuppalapati, Chandrasekar, Vuppalapati, Rajasekar, Kedari, Sharat. (2019). "Machine Learning Infused Preventive Healthcare for High-Risk Outpatient Elderly". In: Proceedings of the 2018 Intelligent Systems Conference (IntelliSys), Volume 2. 10.1007/978-3-030-01057-7_40.

13. Gurina N.A., Frolova E.V., Degryse J.M. “A roadmap of aging in Russia: the prevalence of frailty in community-dwelling older adults in the St. Petersburg district - the "Crystal» study". In: J. Amer. Geriatr. Soc., 2011, Vol. 59 (6), pp. 980-988. 
14. He W., Muenchrath M.N., Kowal P. "U.S. Census Bureau, Shades of Gray: A Cross-Country Study of Health and Well-Being of the Older Populations in SAGE Countries, 2007-2010”. U.S. Government Printing Office, Washington, DC, 2012.

15. Zakharov V.V. "All-Russian Program for the Study of Epidemiology and Therapy of Cognitive Disorders in the Elderly ("Prometheus")". In: Nevrologichesky Zhurnal, 2006, 11, pp. 27-32. (in Russian).
16. Ostapenko V.S. "The prevalence and structure of geriatric syndromes of patients in outpatient facilities in Moscow" [Rasprostranennost' i struktura geriatricheskikh sindromov $\mathrm{u}$ patsiyentov ambulatorno-poliklinicheskikh uchrezhdeniy g. Moskvy], Phd-thesis: 14.01.30, Moscow, 2017, 157 p. (in Russian). 